\title{
Marika Piva, Chateaubriand face aux traditions
}

\section{Fabio Vasarri}

\section{(Q) OpenEdition}

\section{Journals}

\section{Edizione digitale}

URL: http://journals.openedition.org/studifrancesi/2186

DOI: 10.4000/studifrancesi.2186

ISSN: 2427-5856

\section{Editore}

Rosenberg \& Sellier

\section{Edizione cartacea}

Data di pubblicazione: 1 aprile 2014

Paginazione: 157

ISSN: 0039-2944

\section{Notizia bibliografica digitale}

Fabio Vasarri, « Marika Piva, Chateaubriand face aux traditions », Studi Francesi [Online], 172 (LVIII | I)

2014, online dal 01 avril 2014, consultato il 18 septembre 2020. URL : http://journals.openedition.org/ studifrancesi/2186; DOI : https://doi.org/10.4000/studifrancesi.2186

\section{Questo documento è stato generato automaticamente il 18 settembre 2020.}

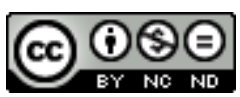

Studi Francesi è distribuita con Licenza Creative Commons Attribuzione - Non commerciale - Non opere derivate 4.0 Internazionale. 


\title{
Marika Piva, Chateaubriand face aux traditions
}

\author{
Fabio Vasarri
}

\section{NOTIZIA}

MARIKA PIVA, Chateaubriand face aux traditions, Passignano sul Trasimeno, Aguaplano, 2012, pp. 174.

1 Nei quattro saggi qui riuniti, derivanti da relazioni congressuali rivedute e ampliate, l'A. prosegue le sue ricerche chateaubriandiane in una prospettiva genetica, filologica e intertestuale.

2 Il primo saggio, Citations en abyme, prolunga la monografia Memorie di seconda mano. La citazione nei "Mémoires d'outre-tombe" di Chateaubriand (2008), tornando sui numerosi prelievi dagli Essais di Montaigne nell'opera in questione. Montaigne si conferma maestro di Chateaubriand anche sul piano della tecnica citazionale. La dettagliata tassonomia include la questione delle citazioni di secondo grado, ossia quelle già presenti nella fonte.

3 Les sources touristiques des "Mémoires d'outre-tombe" si occupa principalmente dell'impronta nel testo di Antoine-Claude Valery, i cui resoconti di viaggio in Italia (1831-1833) sono saccheggiati con disinvoltura dal memorialista nella sezione sull'ambasciata di Roma. E, viceversa, dell'impronta dell'Enchanteur su Valery, i cui numerosi riferimenti costituiscono un documento interessante e poco noto della prima ricezione di Chateaubriand.

4 Le Dernier Troubadour? affronta Les Aventures du dernier Abencérage proponendo un confronto tra l'eroina della novella, Blanca, e la sua ispiratrice Natalie de Noailles quale è presentata nei Mémoires d'outre-tombe, comprese le varianti della copia notarile del 1847. Segue un'analisi delle fonti ispano-moresche e «troubadour», nel quadro del medievalismo del primo Ottocento. 
5 Conclude la raccolta una ricognizione sul tema cruciale dell'esilio (Exil et ambiguité $d u$ déracinement), che attraversa l'opera di Chateaubriand con molteplici accezioni, dalla storia all'allegoria dell'esistenza. In questo quadro di vaste proporzioni, Madame de Staël e Napoleone offrono al memorialista due versioni contrastanti dell'esule. 